\title{
Small-sized reverberation chamber for the measurement of sound absorption
}

\author{
R. del Rey $\bowtie$, J. Alba, L. Bertó, A. Gregori \\ Universitat Politècnica de València, Centre for Physics Technologies: Acoustics, \\ Materials and Astrophysics, Polytechnic School of Gandia, (Valencia, Spain) \\ $\triangle$ roderey@doctor.upv.es
}

\author{
Received 21 June 2016 \\ Accepted 16 January 2017 \\ Available on line 21 September 2017
}

\begin{abstract}
This paper presents the design, construction, calibration and automation of a reverberation chamber for small samples. A balance has been sought between reducing sample size, to reduce the manufacturing costs of materials, and finding the appropriate volume of the chamber, to obtain reliable values at high and mid frequencies. The small-sized reverberation chamber, that was built, has a volume of $1.12 \mathrm{~m}^{3}$ and allows for the testing of samples of $0.3 \mathrm{~m}^{2}$. By using diffusers, to improve the diffusion degree, and automating measurements, we were able to improve the reliability of the results, thus reducing test errors. Several comparison studies of the measurements of the small-sized reverberation chamber and the standardised reverberation chamber are shown, and a good degree of adjustment can be seen between them, within the range of valid frequencies. This paper presents a small laboratory for comparing samples and making decisions before the manufacturing of larger sizes.
\end{abstract}

KEYWORDS: Acoustic Properties; Sound Absorption Coefficient; Characterisation.

Citation/Citar como: del Rey, R.; Alba, J.; Bertó. L.; Gregori, A. (2017) Small-sized reverberation chamber for the measurement of sound absorption. Mater. Construcc. 67 [328], e139 http://dx.doi.org/10.3989/mc.2017.07316

RESUMEN: Cámara reverberante de tamaño reducido para medidas de la absorción sonora. En este trabajo se muestra el diseño, construcción, calibración y automatización de una cámara reverberante para pequeñas muestras. Se ha buscado un equilibro entre la reducción de tamaño de las muestras para disminuir los costes de fabricación de materiales, y el volumen adecuado que permita obtener valores fiables a determinadas frecuencias. La cámara reverberante construida tiene $1.12 \mathrm{~m}^{3}$ de volumen y permite la medida de muestras de $0.3 \mathrm{~m}^{2}$. La colocación de difusores para aumentar el grado de difusión, y la automatización de las medidas, disminuyen los errores de ensayo. Se muestran también diferentes campañas comparativas de medidas en la cámara reverberante para pequeñas muestras y en la cámara normalizada. Puede verse un buen grado de ajuste entre ambas dentro del rango de frecuencias válido. Por tanto, se muestra un pequeño laboratorio que permite comparar muestras y tomar decisiones, antes de realizar la fabricación de grandes tamaños.

PALABRAS CLAVE: Propiedades Acústicas; Coeficiente de Absorción Sonora; Caracterización.

ORCID ID: R. del Rey (http://orcid.org/0000-0001-5907-0677); J. Alba (http://orcid.org/0000-0002-4188-854X); L. Bertó (http://orcid.org/0000-0002-8328-5595); A. Gregori (http://orcid.org/0000-0002-4090-0367)

Copyright: (C) 2017 CSIC. This is an open-access article distributed under the terms of the Creative Commons Attribution License (CC BY) Spain 3.0.

\section{INTRODUCTION}

There is currently considerable interest in the materials and combined solutions used in acoustic absorption. Used in urban and environmental acoustics to reduce noise levels, they form part of noise barriers and other acoustic solutions. They are also used in construction to decrease excess reverberation noise and to condition chambers, adapting them to sound quality standards. The sound 
absorption coefficient is a key feature, which defines these materials and combined solutions. Acoustic solutions for the above-mentioned fields can be designed based on this coefficient, which is measured in diffuse field, taking several criteria into account.

The measurement of the sound absorption coefficient in diffuse field is standardised, and can be obtained in a reverberation chamber under clearly defined conditions. Both European regulation EN ISO 354:2003 (1) and its American equivalent ASTM C432-09a (2) define the characteristics and dimensions of the chamber. The minimum recommended volume of the standardised reverberation chamber is $200 \mathrm{~m}^{3}$ and a test sample surface between 10 and $12 \mathrm{~m}^{2}$ of the material or solution is required. These data can be adjusted depending on the volume of the chamber, increasing the required surface area if the volume is greater.

Today, much effort is being put into designing and manufacturing new recycled materials from different industrial recycling methods, or from plant or natural fibres. Several examples of recycled materials can be found in Del Rey et al. (3) with plastic bottle recycling, in Maderuelo et al. (4) with tyre recycling, or in Del Rey et al. (5) with recycled foams. Other examples of natural based materials can be found in Fatima and Mohanty (6) with jute, in Ramis et al. (7) with kenaf, in Ramis et al. (8) with coconut, in Diaz et al. (9) with reed, in Arenas et al. (10) with cellulose, or in Bulent et al. (11) with tea fibres. In addition, a review of several absorbing materials can be found in works such as that of Arenas \& Crocker (12). There is, therefore, an increasing interest in these new materials, especially in "green-materials", which are largely of natural composition.

Many parameters may affect the mechanical properties of these new materials, mainly those of "green" or eco-materials: their nature, density, humidity conditions, fibres and pore treatment, dispersion of the diameter of the fibres, possible strengthening or meshes, the cure time, etc. Consequently, if the most absorbent conditions for the manufacturing of test samples are to be achieved, a wide variety of materials is required. Moreover, if the assays take place in a standardised reverberation chamber, more than $10 \mathrm{~m}^{2}$ of each sample are needed. This can result in a significant increase in cost.

Finding alternative methods to value sound absorption is a possible solution. Many authors choose to measure the sound absorption coefficient at normal incidence, according to Standard UNE-EN ISO 10534-2:2002 (13) or the American ASTM E1050-10 (14). In this case, the samples are smaller, but this assay may not provide enough information about absorption behaviour in diffuse field or in random incidence, which is relevant for the mentioned applications.

Another option is to take the sound absorption measurements in a small-sized reverberation chamber, reducing the effective sample size and consequently minimising costs, while maintaining diffuse field conditions. The samples will be of $1 \mathrm{~m}^{2}$ at most, instead of $10 \mathrm{~m}^{2}$, depending on the chamber volume.

Small-sized reverberation chambers are not at all new, and there is great interest in them, despite the fact that they are not standardised. In the automotive field, manufacturers use their own standards for these chambers to value sound absorption. An example of this is the GMW14177 (15), where a 6.44 $\mathrm{m}^{3}$ volume chamber is used to take measurements with samples between 0.6 and $2.5 \mathrm{~m}^{2}$. Other examples are Hernandez et al. (16), where a chamber of $3 \mathrm{~m}^{3}$ is built and calibrated and samples between 0.4 and $1.4 \mathrm{~m}^{2}$ are tested, Bradley et al. (17), where the chamber volume is $1.71 \mathrm{~m}^{3}$ and maximum diffusion conditions are requested, or Pacheco et al. (18), where the chamber volume is reduced to $0.96 \mathrm{~m}^{3}$, the size of samples is $0.3 \mathrm{~m}^{2}$ and it is used to characterise absorbents based on vegetable fibres, mainly coconut fibres.

This paper presents the building and calibration of a small-sized reverberation chamber. Balance is sought between chamber volume and sample size, but without changing diffuse field behaviour. The chamber was built with reference to the standardised reverberation chamber of the Higher Polytechnic School of Gandia at the Universitat Politècnica de València. Moreover, the data obtained with the small-sized chamber will be compared with that obtained from this one, to evaluate similarities between their results and any further improvements that may be required.

Originally, this small-sized chamber was built for the European NOISEFREETEX project (19), which dealt with acoustic solutions with nanofibre veils that require high production costs. It is currently being used as a sample testing chamber for the European WOOL4BUILD (20) project, to select the most competitive sheep's wool before taking measurements in the standardised reverberation chamber, thus decreasing the initial needs of sample production. In order to compare sound absorption values of different absorbent materials, a research phase is essential. To do this, it suffices to know the absorption values of the materials from mediumhigh frequencies.

At present, this small-sized reverberation chamber is being used to characterise materials, which are to be used in the automotive field. In these cases, the manufacturers' specifications must be fulfilled (15, 21 ), and (22)). In the automotive field, it also suffices to know the absorption values from mediumhigh frequencies. 


\section{CONSTRUCTION OF A SMALL-SIZED REVERBERATION CHAMBER}

The reverberation chamber is an acoustic laboratory, one of the most widely used laboratories for determining the sound absorption coefficient of any noise-reducing device or material. To specify a measurement method for the absorption coefficient of acoustic materials used for treating ceiling or walls, there must be well-defined assay conditions in the chamber. One of the most important conditions is the presence of a diffuse sound field (1-2). The design of a laboratory that fulfils the diffuse field condition for a controlled frequency range is shown below. The volume of this chamber is $1.12 \mathrm{~m}^{3}$, and its surface, $6.74 \mathrm{~m}^{2}$. The diffuse field conditions were achieved in the chamber, and so the guidelines for the standardised procedure were followed (1-2), requiring only $0.3 \mathrm{~m}^{2}$ samples.

\section{Design}

There is a section in the standardised procedure, which describes the design of the reverberation chamber. The shape of the chamber must fulfil the following condition [1]:

$$
I_{\max }<1.9 \mathrm{~V}^{1 / 3}
$$

Where $I_{\max }$ is the greatest length of any straight line segment inscribed into the chamber, and $\mathrm{V}$ is the chamber volume.

Furthermore, in order to obtain a uniform distribution of the natural frequencies in the chamber, there cannot be two dimensions there whose proportion coincides with the first integers (1-2). The characteristics of the diffusers are described in the Normative Annex. The diffusers help to improve the sound field diffusion, and have to be thin surfaces of low sound absorption. The recommended additional surface with diffusers is between $15 \%$ and $25 \%$ of the total chamber surface.

Meeting these conditions and taking the standardised reverberation chamber of the Higher Polytechnic School of Gandia, which has a volume of $238 \mathrm{~m}^{3}$, as a reference, the design of the small-sized reverberation chamber is shown in Figure 1 a. Figure $1 \mathrm{~b}$ shows the small-sized chamber when built.

One of the features of the chamber design that was most carefully studied was the acoustic insulation, so as to avoid external noise interference in the test conditions. The walls of the chamber were built as self-supporting lightweight partitions. The wall's structure is made of (from outside to inside): plasterboard, an absorbent material of 4 $\mathrm{cm}$ thick thermally fused fibres, plasterboard, and a $4 \mathrm{~mm}$ thick composite Alucobond coating. This design allows the difference in the level between background noise and SPL to remain constantly at more than 70 or $80 \mathrm{~dB}$. These differences in level guarantee easy registration of both T30 and T20 decays.

After studying how the different combinations of source and microphones influenced the Degree of Diffusion, Gd, the distribution of the diffusers and the design was made. This parameter, Gd, links the first fall times, EDT, with those which last longer, T20. The closer the Gd value is to 1 , the more diffusion increases there are in the sound field. Table 1 shows the Gd values for the designed chamber [2].

$$
G d=\left|1-\frac{|E D T-T 20|}{(E D T+T 20) / 2}\right|
$$

In order to define the minimum required distances between microphones, sources and the reflecting surfaces, the minimum distances described in (1-2) were resized, with a factor of 1:6. To design the diffusers, the dimensions were resized bearing in mind their surface area, with a factor of $1: 36$, and so a)

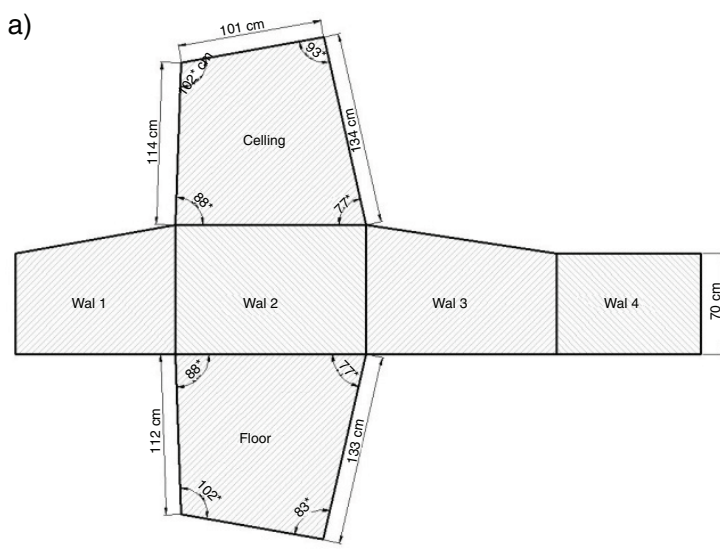

b)

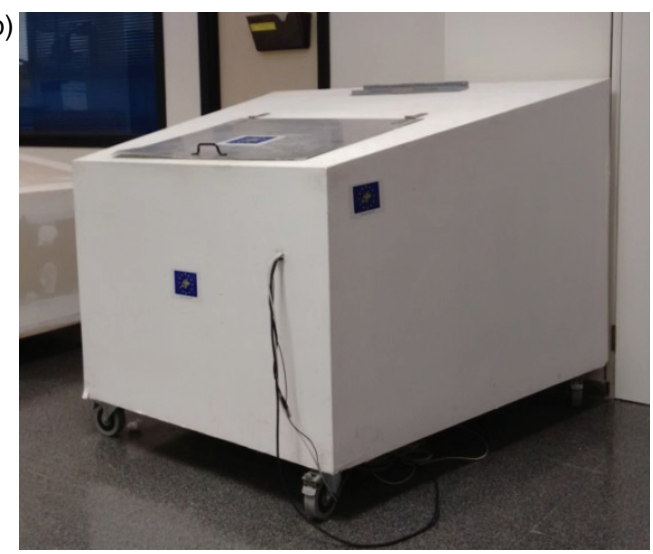

Figure 1. Design and dimensions of the small-sized reverberation chamber seen from above (figure 1 a/left). Outside view of the reverberation chamber when built (figure $1 \mathrm{~b} /$ right). 
five wood panels with low absorption were installed. Their surface represents $3.5 \%$ of the whole chamber surface. It is important to bear in mind that the loudspeaker being used is not omnidirectional, as is specified in (1-2). The source used is a Genelec 6010 $\mathrm{A}$, which has a critical radius of approx. $0.4 \mathrm{~m}$. This distance was also taken into consideration to avoid being in the near-field zone. The loudspeaker has a free field frequency response of $74 \mathrm{~Hz}-18 \mathrm{kHz}$.

\section{Automation}

In a test laboratory like the reverberation chamber, it is necessary to work under controlled conditions, in a comfortable space. Moreover, to make work easier and reduce errors and testing effort, it is preferable to use an automation system. In order to optimise the measurement tests in this small-sized reverberation chamber, the installation of an automation system was considered, to control the microphone's motion from outside the chamber, and to take measurements

Table 1. Diffusion Degree

\begin{tabular}{lc}
\hline Frequency $\mathbf{( H z )}$ & Diffusion Degree \\
\hline 100 & 0.09 \\
125 & 0.19 \\
160 & 0.42 \\
200 & 0.86 \\
250 & 0.80 \\
315 & 0.81 \\
400 & 0.82 \\
500 & 0.98 \\
630 & 0.98 \\
800 & 0.91 \\
1000 & 0.89 \\
1250 & 0.89 \\
1600 & 0.89 \\
2000 & 0.94 \\
2500 & 0.99 \\
3150 & 0.97 \\
4000 & 0.98 \\
5000 & 1.00 \\
\hline
\end{tabular}

without needing to enter the chamber, which has a volume of little more than $1 \mathrm{~m}^{3}$.

The automation of the microphone's motion was performed with the introduction of a webcam, model Aqprox IP01WV4, which was screwed onto the ceiling of the small-sized reverberation chamber, and which has a rotary motor and is controlled by IP. A tube that is $10 \mathrm{~mm}$ in diameter and $450 \mathrm{~mm}$ long is attached to the webcam. Inside the tube is the microphone, which has a preamplifier inside it, at the end. The IP online connection to the webcam allows us to see the inside of the reverberation chamber and the position of the microphone in real-time through any internet explorer, since the microphone moves at the same time as the webcam. Figure 2 shows a detail of the webcam (Figure 2 a), a detail of the inside of the reverberation chamber with the automation system, diffusers and loudspeaker (Figure 2 b), and a screenshot of the software that controls the webcam from the outside of the reverberation chamber (Figure $2 \mathrm{c}$ ).

\section{Calibration}

The automation of the microphone's motion allows us to study different combinations of sourcemicrophone positions, to register the sound pressure level. To this end, seventy-eight different measurement positions were evaluated. Among them, six different microphone positions for two different source positions were chosen. The distribution of the twelve measurement positions is shown in Figure 3.

Considering these twelve measurement positions, the Diffusion Degree (Table 1) and the sound absorption area (Table 2) are evaluated. The equivalent sound absorption area of the empty reverberation chamber, A1, must meet the well-defined criteria. The values of A1 cannot have differences larger than $15 \%$ between contiguous one-third octaves. Table 2 shows the A1 values for the small-sized reverberation chamber, and the difference between its contiguous one-third octave bands values. It is obvious that only the one-third octave band value of $315 \mathrm{~Hz}$ does not fulfil the established lineal criterion (1-2). However, this frequency is outside of the valid chamber design range. As we know (1-2), the lowest valid frequency in a reverberation chamber is the one whose wavelength is less than (a)

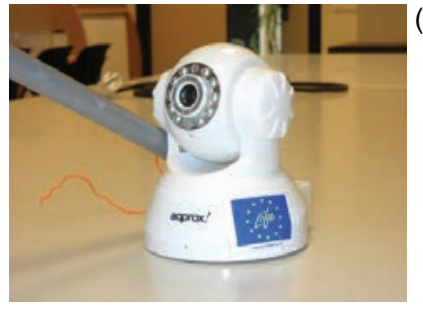

(b)

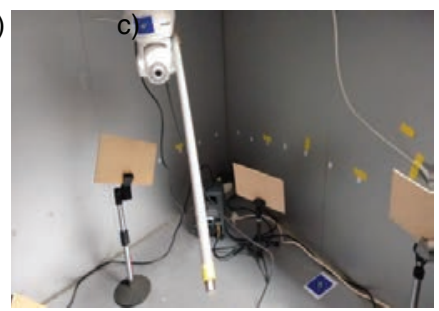

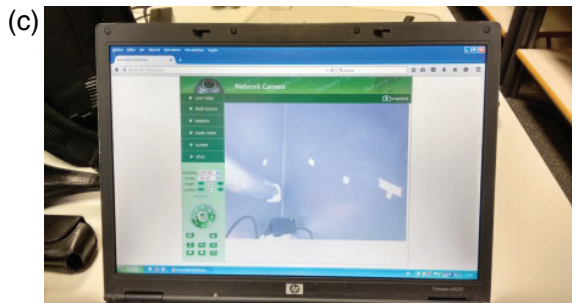

FIGURE 2. Webcam used (Figure $2 \mathrm{a} / \mathrm{left}$ ), inside the reverberation chamber (Figure $2 \mathrm{~b} /$ centre) and screenshot of the software that controls the webcam from the outside (Figure $2 \mathrm{c} /$ right). 


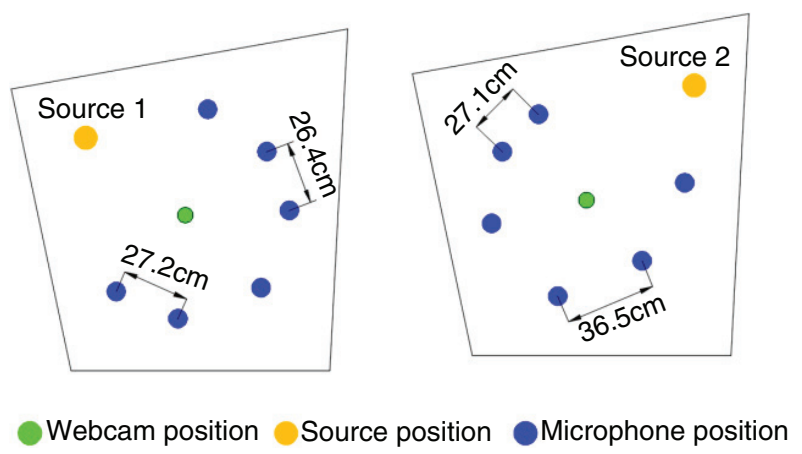

FIGURE 3. Microphone positions to take the measurements after installing the automated motion system and the diffusers inside the chamber.

TABLE 2. $\mathrm{A} 1\left(\mathrm{~m}^{2}\right)$ and difference between octaves $(\%)$

\begin{tabular}{lcc}
\hline Frequency (Hz) & $\left.\mathbf{A 1} \mathbf{( m}^{\mathbf{2}}\right)$ & $\begin{array}{c}\text { Difference between its } \\
\text { contiguous one-third octave } \\
\text { bands values } \\
\mathbf{( \% )}\end{array}$ \\
\hline 100 & 0.79 & --- \\
125 & 0.43 & 5.6 \\
160 & 0.38 & 2.4 \\
200 & 0.36 & 3.0 \\
250 & 0.38 & 4.1 \\
315 & 0.35 & 17.0 \\
400 & 0.23 & 4.0 \\
500 & 0.21 & 0.6 \\
630 & 0.22 & 14.5 \\
800 & 0.28 & 9.1 \\
1000 & 0.33 & 6.8 \\
1250 & 0.38 & 6.7 \\
1600 & 0.43 & 4.3 \\
2000 & 0.46 & 0.2 \\
2500 & 0.46 & 7.1 \\
3150 & 0.53 & 0.2 \\
4000 & 0.53 & 2.3 \\
5000 & 0.51 & 0.0 \\
\hline
\end{tabular}

the length of the shortest edge of the chamber. In our small reverberation chamber, this value is 0.70 metres, therefore the lowest cut-off frequency should be $485 \mathrm{~Hz}$ (23). This can be proved by analysing the results of the experiments undertaken in this project. Table 1 shows an example. It shows how the Diffusion Degree of the first three one-third octave values is far from the unit. However, the Diffusion Degree presents higher values from approximately $400 \mathrm{~Hz}-5 \mathrm{kHz}$.

\section{RESULTS}

To verify the construction, configuration and position of the chosen measurements of the small-sized reverberation chamber, eight different materials were
TABle 3. Density $\left(\mathrm{g} / \mathrm{m}^{2}\right)$ and thickness $(\mathrm{mm})$ of the chosen materials used for the setting-up of the small-sized reverberation chamber.

\begin{tabular}{lcc}
\hline Material & $\begin{array}{c}\text { Density } \\
\left(\mathbf{g} / \mathbf{m}^{2}\right)\end{array}$ & $\begin{array}{c}\text { Thickness } \\
(\mathbf{m m})\end{array}$ \\
\hline Mineral Wool (Wool80) & 1400 & 80 \\
Mineral Wool (Wool40) & 1400 & 40 \\
Recycled polyester fibre I (I1400) & 1400 & 70 \\
Recycled polyester fibre I (I700) & 700 & 25 \\
Recycled polyester fibre I(I600) & 600 & 30 \\
Recycled polyester fibre I(I400) & 400 & 40 \\
Recycled polyester fibre I(I300) & 300 & 20 \\
$\begin{array}{l}\text { Recycled polyester fibre RC } \\
\text { (RC250) }\end{array}$ & 250 & 10 \\
\hline
\end{tabular}

used for testing. Six of those materials were made of recycled polyester and the other two of mineral wool. The polyester samples may have been treated as fireresistant (I) or not (RC). The specifications regarding the density and thickness of these samples can be seen in Table 3. The mineral wool samples were chosen as the material's behaviour with sound absorption is well-known, and the authors of this paper carried out detailed studies on the chosen recycled polyester fibres (3). Table 3 shows how the small-sized reverberation chamber was validated, using the eight chosen materials which have different densities (high/ medium/low).

Figure 4 shows the correlation lines relating the sound absorption values of the standardised chamber with those of the small-sized chamber, for each one-third octave. The OX axis represents the standardised reverberation chamber values $\left(\mathrm{V}=238 \mathrm{~m}^{3}\right)$. The OY axis represents the small-sized reverberation chamber values $\left(\mathrm{V}=1.12 \mathrm{~m}^{3}\right)$. If the values match for all the samples, taking into consideration each of the one-third octave bands, the regression line will have almost no dispersion.

Table 4 shows the " $r$ squared value" or coefficient of determination. In statistics, the coefficient of determination indicates how well data points fit a statistical model, which, in this case, is simply a line. It is a statistic that is used in the context of statistical models whose main purpose is either the prediction of future outcomes or the testing of hypotheses on the basis of other related information. It provides a measure of how well observed outcomes are replicated by the model. There are several different definitions of this parameter. Fundamentals can be found for descriptive statistics, where the $\mathrm{r}$ squared value is also defined. In such cases, the coefficient of determination ranges from $0-1$. To the detailed study in this project, an $r$ squared value equal to the unit will mean that the sound absorption values obtained from the small-sized reverberation chamber are identical to the sound absorption values obtained from the standardised reverberation 
(a)

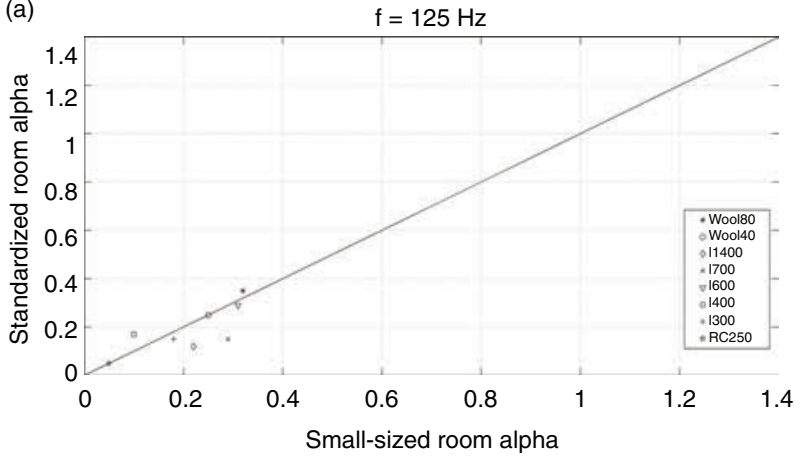

(c)

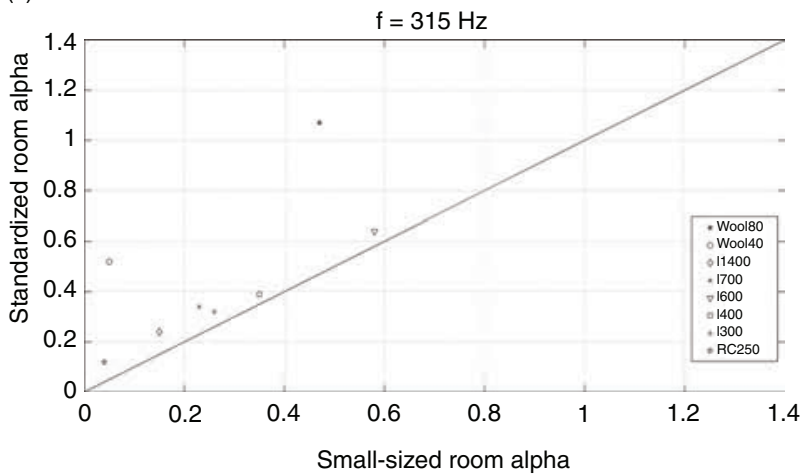

(e)

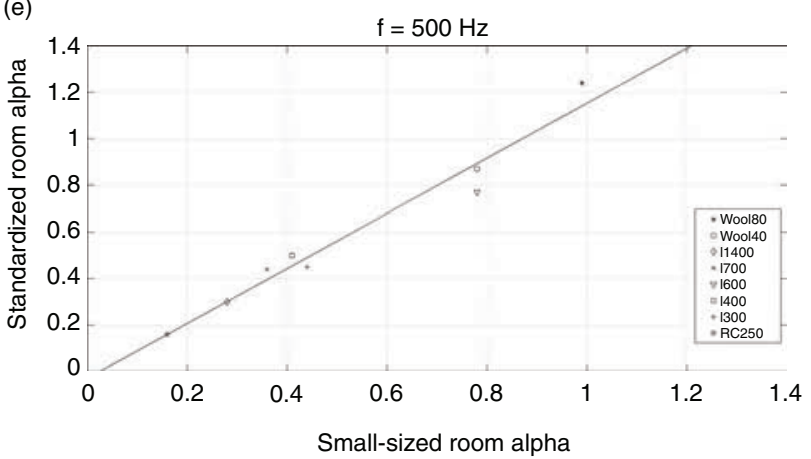

(g)

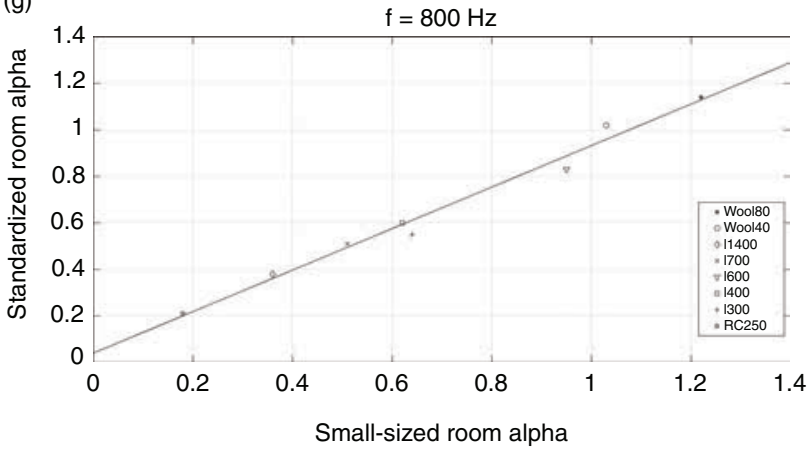

(b)

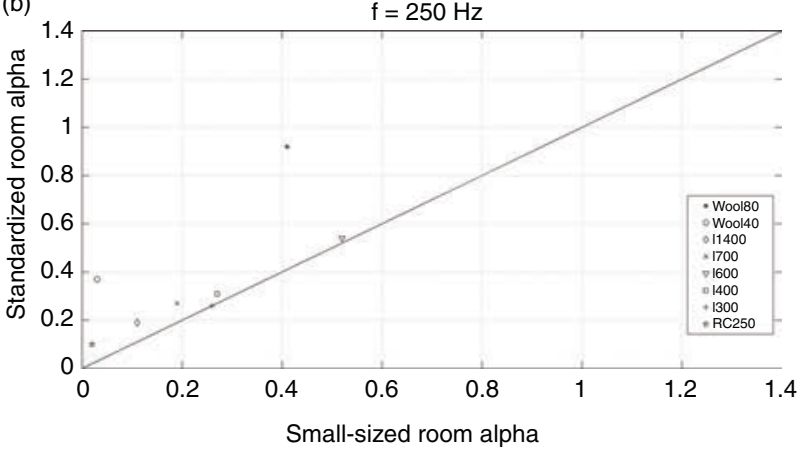

(d)

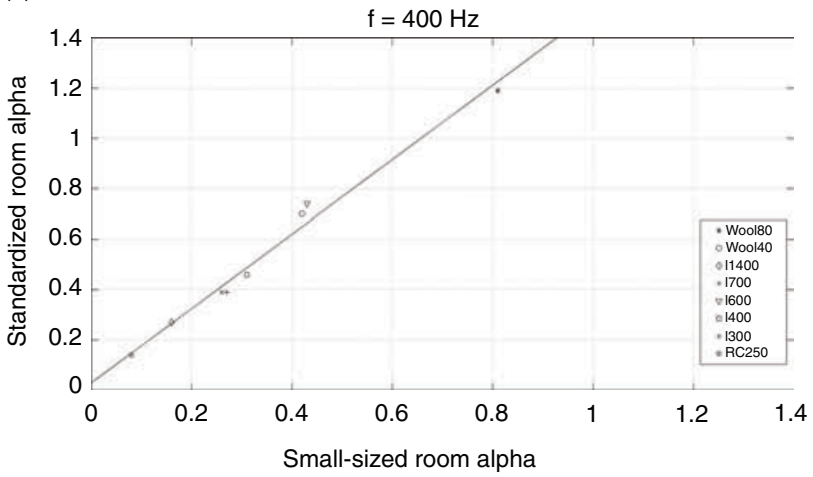

(f)

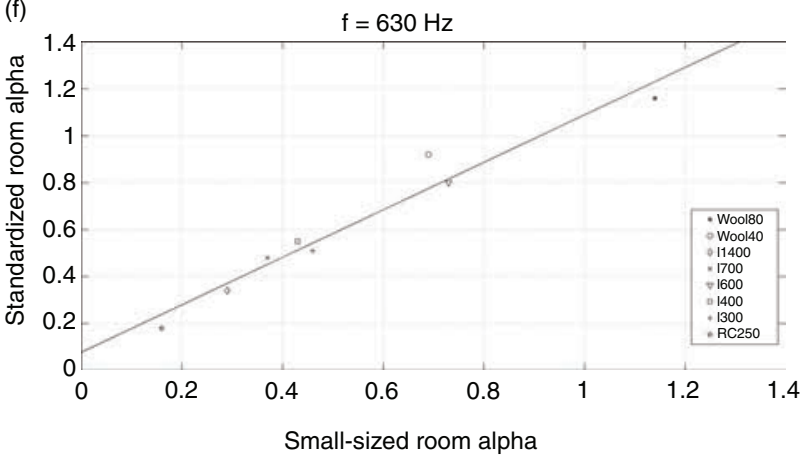

(h)

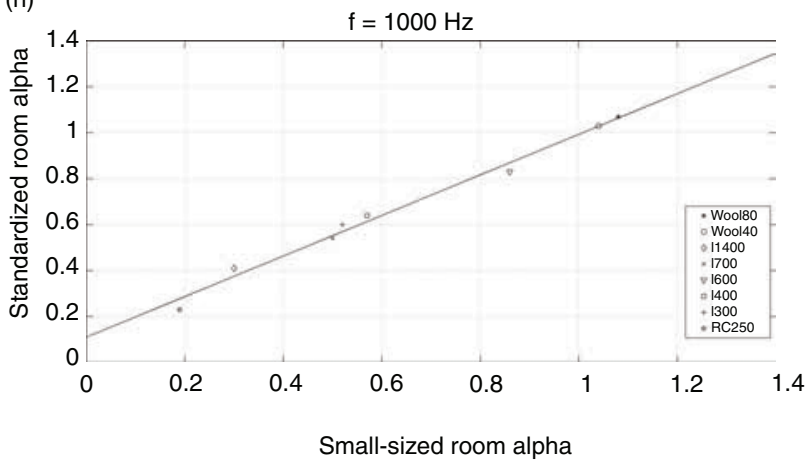

FIGURE 4. Correlation lines of the standardised absorption/absorption of the small-sized chamber, for each one-third octave band, from $125 \mathrm{~Hz}-5000 \mathrm{~Hz}$.

(Continued) 
(i)

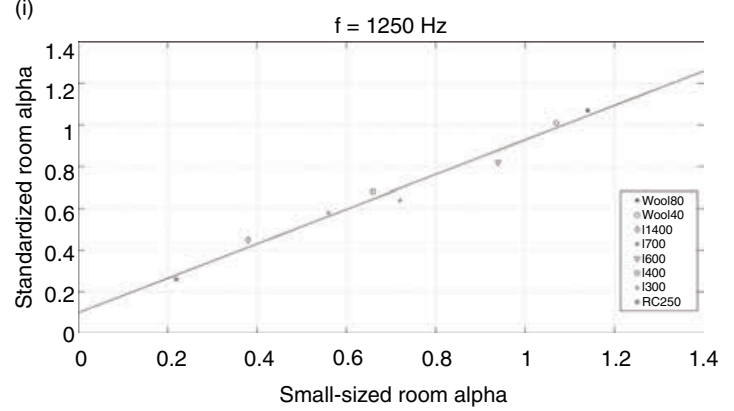

(k)
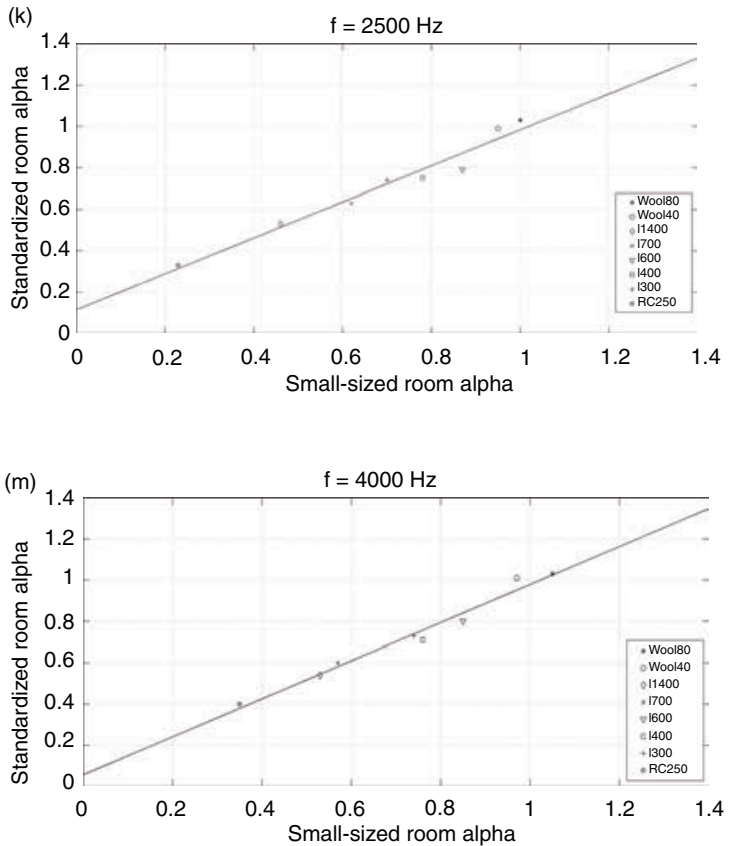

(j)

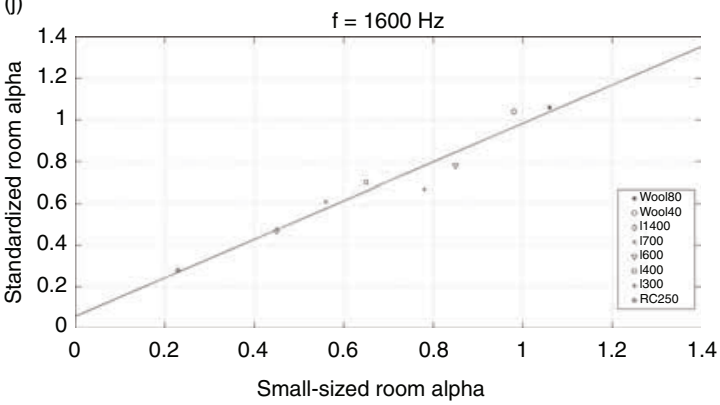

(I) $f=3150 \mathrm{~Hz}$

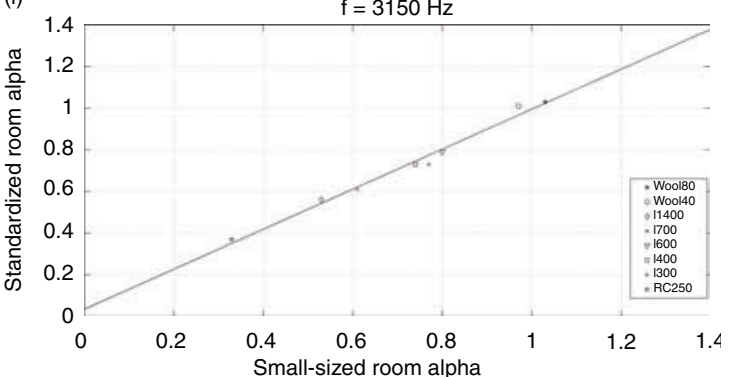

(n)

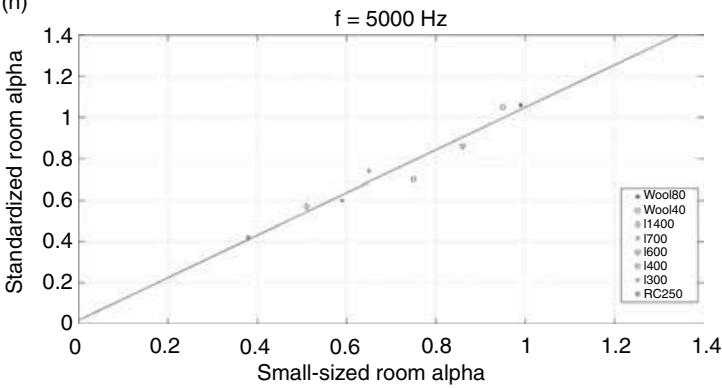

FIGURE 4. (Continued) Correlation lines of the standardised absorption/absorption of the small-sized chamber, for each one-third octave band, from $125 \mathrm{~Hz}-5000 \mathrm{~Hz}$.

TABLE 4. $\mathrm{R}^{2}$ squared values of the lines showed in Figure 4.

\begin{tabular}{lc}
\hline $\mathbf{f}(\mathbf{H z})$ & $\mathbf{R}^{\mathbf{2}}$ Squared \\
\hline 125 & 0.58 \\
250 & 0.50 \\
315 & 0.46 \\
400 & 0.98 \\
500 & 0.96 \\
630 & 0.95 \\
800 & 0.98 \\
1000 & 0.99 \\
1250 & 0.98 \\
1600 & 0.95 \\
2000 & 0.98 \\
2500 & 0.96 \\
3150 & 0.99 \\
4000 & 0.98 \\
5000 & 0.95 \\
\hline
\end{tabular}

chamber, taking into consideration one specific central frequency.

Figure 5 compares the standardised sound absorption values with the small-sized sound absorption values, for the eight materials of Table 3 .

\section{CONCLUSIONS}

This paper has detailed the design, construction and automation of a small-sized reverberation chamber. The chamber is intended to measure the sound absorption coefficient of small samples, which have high production costs when large quantities are required. Therefore, the design of the chamber prioritises the reduction of its dimensions, while maintaining the acoustic characteristics that will achieve accurate measurements in medium-high frequencies. The standardised reverberation chamber of the Higher Polytechnic School of Gandia was used as a reference when designing the small chamber. The volume of the chamber was reduced 
(a)

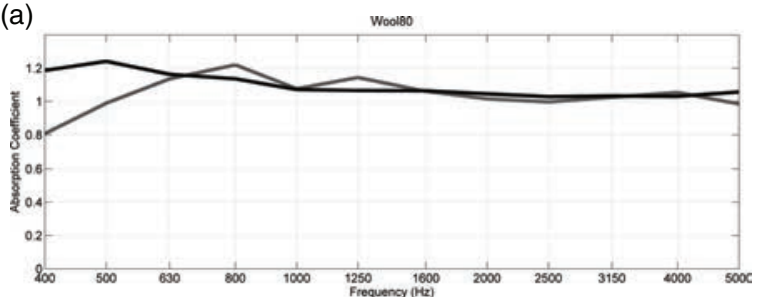

(c)

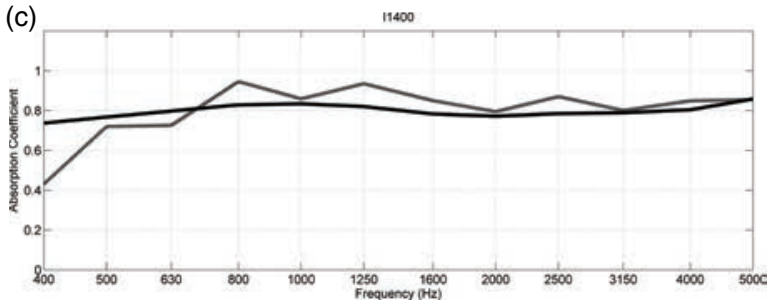

(e)

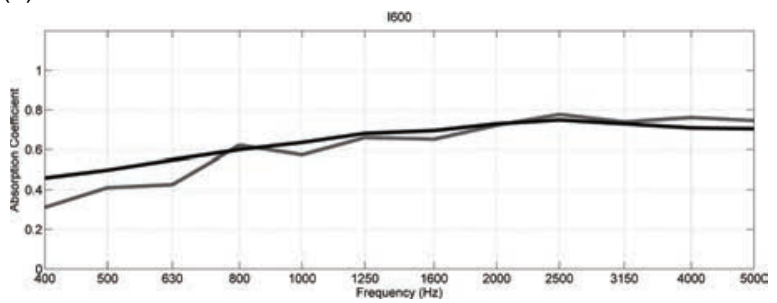

(g)

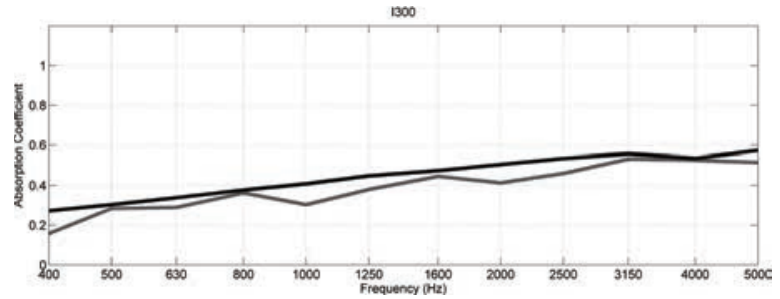

(b)

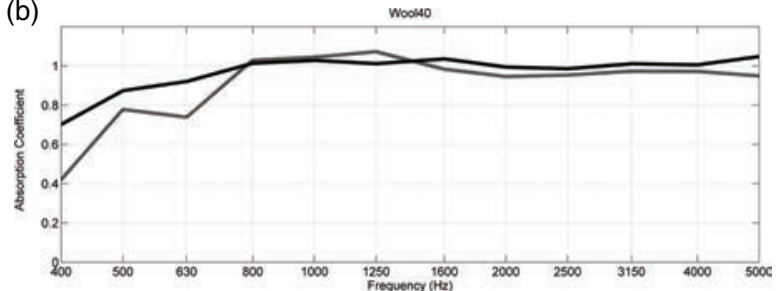

(d)

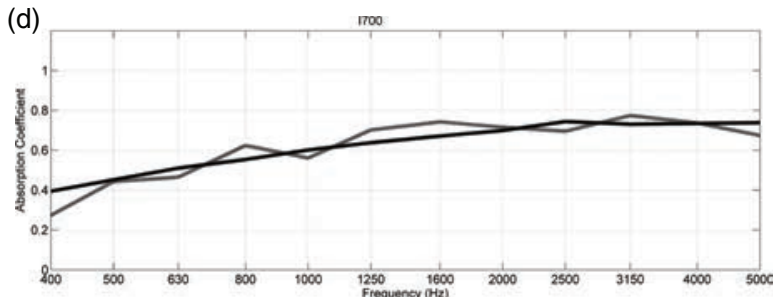

(f)

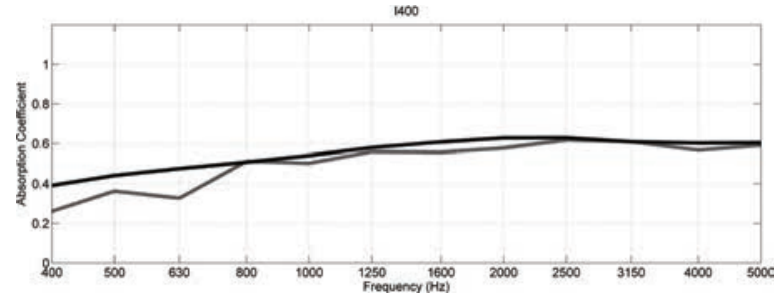

(h)

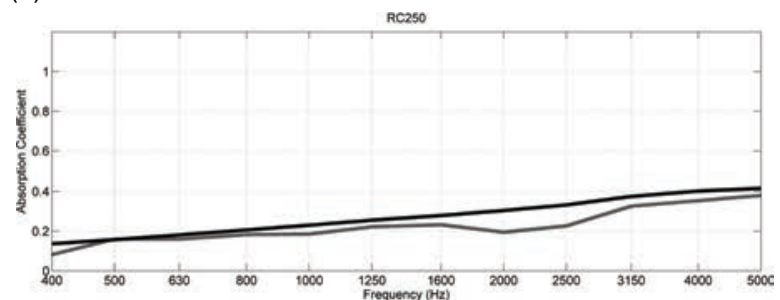

FIGURE 5. Values of the sound absorption coefficient obtained in the standardised chamber (continuous line) and values of the sound absorption coefficient obtained in the small-sized reverberation chamber (discontinuous line).

to $1.12 \mathrm{~m}^{3}$, as shown in the referenced papers, whose works involved the use of very small samples.

In order to optimise the chamber and improve diffusion, small-scale diffusers were installed. Also, the procedure was automatized to avoid changing the measurement conditions during the assays. As we have seen above, the Diffusion Degree improved and the reliability of the assay was increased.

Several comparison studies between the measures of the sound absorption coefficient in the small-sized reverberation chamber and those in the standardised reverberation chamber were carried out. Some results of those comparisons, which were conducted with mineral wool and polyester wool, are shown in this paper. As can be seen, the measurements of the small-sized chamber coincide well with the measurements of the standardised chamber, in the range of frequencies in which the smallsized reverberation chamber fulfils the diffusion conditions. Several of those studies were carried out with other materials, and provided similar results.

To sum up, the construction of a reverberation chamber allowing low-cost assays has been achieved. This small-sized reverberation chamber permits the testing and comparison of small samples of materials, so that a few of them can later be chosen to be tested in a standardised reverberation chamber.

\section{ACKNOWLEDGEMENTS}

This project involved the contribution of the European Union's financial instrument, LIFE: 'LIFE $09 \mathrm{ENV/ES/461:} \mathrm{Demonstrative} \mathrm{solutions} \mathrm{to} \mathrm{reduce}$ noise pollution in industrial, using finishing technologies in textile materials' and that of the European project 'WOOL4BUILD ECO/13/630249/SI2.681252, CIP-ECO-INNOVATION: Improved isolation material for eco-building based on natural wool'. 


\section{REFERENCES}

1. EN ISO 354:2003. Acoustics - Measurement of sound absorption in a reverberation room. TC: ISO/TC 43/SC 2, ICS: 91.120.20.

2. ASTM C423-09a Standard Test Method for Sound Absorption and Sound Absorption Coefficients by the Reverberation Room Method. Developed by Subcommittee: E33.01.

3. Del Rey, R.; Alba, J.; Ramis, J.; Sanchis, V.J. (2011). New absorbent acoustic materials from plastic bottle remnants. Mater. Construcc. 61 [304], 547-558. http://dx.doi. org/10.3989/mc.2011.59610

4. Maderuelo, R.; Nadal, A.V.; Crespo, J.E.; Parres, F. (2012). A novel sound absorber with recycled fibers coming from end of life tires (ELTs). Applied Acoustics. 73, 402-408. http://dx.doi.org/10.1016/j.apacoust.2011.12.001

5. Del Rey, R.; Alba, J.; Arenas, J.P.; Sanchis, V.J. (2012). An empirical modelling of porous sound absorbing materials made of recycled foam. Appl. Acoust.. 73, 604-609. http:// dx.doi.org/10.1016/j.apacoust.2011.12.009

6. Fatima, S.; Mohanty, A.R. (2011). Acoustical and fire-retardant properties of jute composite materials. Appl. Acoust.. 72, 108-114. http://dx.doi.org/10.1016/j. apacoust.2010.10.005

7. Ramis, J.; Alba, J.; Del Rey, R.; Escuder, E.; Sanchis, V.J. (2010). Nuevos materiales absorbentes acústicos basados en fibra de kenaf. Mater. Construcc. 60 [299], 133-143. http://dx.doi.org/10.3989/mc.2010.50809

8. Ramis, J.; Del Rey, R.; Alba, J.; Godinho, L.; Carbajo, J. (2014). A model for acoustic absorbent materials derived from coconut fiber. Mater. Construcc. 64 [313]. http:// dx.doi.org/10.3989/mc.2014.00513

9. Díaz, C.; Jimenez, M.; Navacerrada, M.Á. Pedrero, A. (2012). Propiedades acústicas de los paneles de carrizo"" Acoustic properties of reed panels. Mater. Construcc. 62 [305] 55-66. http://dx.doi.org/10.3989/mc.2010.60510

10. Arenas, J.P.; Rebolledo, J.; Del Rey, R.; Alba, J. (2014). Sound Absorption Properties of Unbleached Cellulose Loose-Fill Insulation Material. BioResources. 9 [4] 6227-6240. http://ojs.cnr.ncsu.edu/index.php/BioRes/ article/view/BioRes_09_4_6227_Arenas_Sound_ Absrption_Properties_CelluTose/3020

11. Bulent, E.; Aykut, K.; Haluk, K. (2012). Improving Sound Absorption Property of Polyurethane Foams by Adding Tea-Leaf Fibers. Arch. Acoust.. 37 [4] 515-520. http:// dx.doi.org/10.2478/v10168-012-0052-1
12. Arenas, J.P.; Crocker, M.J. (2010). Recent trends in porous sound absorbing materials for noise control. Sound Vib.. 44 [7] 13-17. http://www.sandv.com/downloads/1007croc.pdf

13. ISO 10534-2:1998. Acoustics -- Determination of sound absorption coefficient and impedance in impedance tubes -- Part 2: Transfer-function method. TC: ISO/TC 43/SC 2, ICS: 17.140 .01 .

14. ASTM E1050-10. Standard Test Method for Impedance and Absorption of Acoustical Materials Using A Tube, Two Microphones and A Digital Frequency Analysis System. . Developed by Subcommittee: E33.01

15. GMW14177 3rd Edition, October 1, 2014 Random Incidence Sound Absorption Evaluation Test Procedure. Published by GMW - General Motors Worldwide.

16. Hernández, D.; Liu, E.J.; Huang, J.H.; Liu, Y.C. (2015). Design and Construction of a Small Reverberation Chamber Applied to Absorption and Scattering Acoustic Measurements. Advanced Materials Research. 1077. 197-202. http://dx.doi.org/10.4028/www.scientific.net/ AMR.1077.197

17. David T. Bradley, Markus Müller-Trapet, Jacob Adelgren and Michael Vorländer. (2014). Effect of boundary diffusers in a reverberation chamber: Standardized diffuse field quantifiers. J. Acoust. Soc. Am. 135. http://dx.doi. org/10.1121/1.4866291

18. Pacheco Bastos, L.; Da Silva Vieira de Melo, G.; Sure Soeiro, N. (2012). Panels Manufactured from Vegetable Fibers: An Alternative Approach for Controlling Noises in Indoor Environments. Advances in acoustic and vibration. 2012, Article ID 698737 http://dx.doi. org/10.1155/2012/698737

19. LIFE09 ENV/ES/000461 (2011). Demonstrative solutions to reduce noise pollution in industrial areas, using finishing technologies in textile materials. http://noisefreetex.aitex. net- (June 21, 2016)

20. WOOL4BUILD. Improved isolation material for ecobuilding based on natural wool http://www.wool4build.eu - (June 21, 2016)

21. D49-1977. PSA PEUGEOT-CITROËN. Methodes d'Essai Matieres. Materiaux fibreux et Alveolaires. Absorption Acoustique en champs diffuse.

22. 1848 495.6. Technische liefervorschrift. Technical delivery. TL Faserviles BMW für Schalli. Specs Fibre Flee Soundins. December 2013.

23. Skålevik, M. (2011). Schroeder Frequency revisited. International Congress Forum Acustikum - Aalborg, Denmark - 2011. 